782

Furness, G. (1958). J. gen. Microbiol. 18, 782-786

\title{
The Transfer of Motility and Tyrosine Requirement to Escherichia coli Strain B by Recombination with $E$. coli Strain K 12
}

\author{
By G. FURNESS \\ The Wright-Fleming Institute of Microbiology, St Mary's Hospital Medical School, \\ Paddington, London, $W .2$
}

SUMMARY: Motile recombinants may be obtained by crossing Escherichia coli strain $\mathrm{K12}, \mathrm{F}+$, with the non-flagellated strain $E$. coli strain $\mathrm{B}, \mathrm{F}-$. The flagella of the recombinants have the same antigenic pattern as those of the $F+$ parent and the locus controlling motility is linked to loci controlling tyrosine requirement and fermentation of arabinose and galactose $\left(\mathrm{gal}_{5}\right)$.

Motility may be transduced to non-motile strains of Salmonella by phage grown on motile Salmonella strains (Stocker, Zinder \& Lederberg, 1953). The majority of the motile clones thus obtained produce flagella having the antigenic composition of the motile parent stock from which the non-motile recipient strain was derived by mutation. Transduction therefore normally reveals their inherent antigenic pattern. By using suitable selective techniques, in some cases, a minority of motile recombinants having flagella of the antigenic pattern of the bacteria on which the phages were propagated (donor strain) can be demonstrated.

These observations suggested that motility might similarly be transferred by recombination between mutants of Escherichia coli strain $\mathrm{K} 12$ and mapped as another marker on the bacterial chromosome. However, all mutants of strain K12 were found to become motile on inoculating Craigie tubes. E. coli strain B, on the other hand, never mutated to motility but acquired motility when incubated with motile strain K12 F + mutants (Furness \& Rowley, 1955). All the motile progeny had flagella of the same antigenic pattern as the $\mathbf{F}+$ parent but linkage with other characters could not be shown. Linkage has been further investigated by using auxotrophic strains of $E$. coli strain B. This paper reports the results of experiments in which it has been found that motility is linked to other markers on the bacterial chromosome, namely tyrosine requirement and ability to ferment arabinose and galactose.

\section{METHODS}

Strains of Escherichia coli strain B. Both strains were F-, non-motile, resistant to $500 \mu \mathrm{g}$. streptomycin $/ \mathrm{ml}$., fermented lactose, arabinose, galactose, xylose and mannitol but not maltose $\left(\mathrm{lac}^{+}, \mathrm{arab}^{+}, \mathrm{gal}^{+}, \mathrm{xyl}^{+} \mathrm{mtl}^{+}, \mathrm{mal}^{-}\right)$and were sensitive to all of the $T$ series of phages. $E$. coli $B / \mathbf{S}^{\mathbf{R}} \mathbf{F}-$ grows on minimal medium (Davis \& Mingioli, 1950). E. coli $\mathrm{B}$ mutant $615 / \mathrm{S}^{\mathbf{B}} \mathbf{F}$ - was kindly made available to us by $\mathrm{Dr}$ de Haan and was auxotrophic for tyrosine and methionine (de Haan, 1955). 
Strains of Escherichia coli $K 12$. Strain W677 was auxotrophic for threonine, leucine and vitamin $\mathrm{B}_{1}\left(\mathrm{~T}^{-} \mathrm{L}^{-} \mathrm{B}_{1}^{-}\right)$, did not ferment lactose, arabinose, galactose, maltose, xylose and mannitol ( $\left.\mathrm{lac}^{-}, \mathrm{arab}^{-}, \mathrm{gal}_{5}^{-}, \mathrm{mal}^{-}, \mathrm{xyl}^{-}, \mathrm{mtl}^{-}\right)$and was resistant to phages $T_{1}$ and $T_{5}\left(V_{1,5}^{R}\right.$; Clowes \& Rowley, 1954; Lennox, 1955). It was streptomycin sensitive and $\mathbf{F}+$, mating with $E$. coli $\mathrm{B}$ strains. To ensure that all organisms were fully motile it had been repeatedly passaged through Craigie tubes.

Media. Minimal medium was that of Davis \& Mingioli (1950) and the formula of Lederberg (1950) was used for eosin + methylene-blue sugar-containing media. The minimal medium was supplemented with $20 \mu \mathrm{g} . / \mathrm{ml}$. of tyrosine or methionine when required. Craigie tubes were prepared as described by Tulloch (1939) using nutrient broth solidified with $0.5 \%$ Difco agar. Semi-solid gelatin agar was made by the method of Stocker et al. (1953). All streptomycin media contained $500 \mu \mathrm{g}$. streptomycin $/ \mathrm{ml}$.

Recombination techniques. Using overnight cultures $3 \mathrm{ml}$. of coli $\mathbf{B}$ parent and $6 \mathrm{ml}$. F + parent were mixed, incubated $\frac{1}{2} \mathrm{hr}$. at $37^{\circ}$, diluted with $45 \mathrm{ml}$. broth and incubation continued for a further $3 \frac{1}{2} \mathrm{hr} .8 \mathrm{ml}$. of the mixture and $5 \mathrm{ml}$. of each parent, as controls, were centrifuged. Further stages of the technique depended on the recombinants to be selected, as follows.

(a) Selection of motile recombinants. The deposits after centrifugation were spread by loop in arcs (Stocker et al. 1953) on plates of semi-solid gelatin agar containing streptomycin to eliminate the $\mathbf{F}+$ parent. The plates were incubated at $37^{\circ}$ for $24 \mathrm{hr}$. and left at room temperature for a further $72 \mathrm{hr}$.

(b) Selection of mono-auxotrophic recombinants. The organisms were washed three times in minimal salts, resuspended in approximately one-tenth the original volume and $0.1 \mathrm{ml}$. amounts were spread on minimal medium plates supplemented as necessary. All plates were incubated at $37^{\circ}$ for $42 \mathrm{hr}$.

Purification of recombinants. Motile or mono-auxotrophic recombinants were purified by picking a discrete colony after plating out on nutrient agar. After checking that the purified strain still showed the recombinant characters, it was tested for the unselected markers by standard methods for testing sugar fermentations, streptomycin resistance, phage resistance and nutritional requirements; motility was tested by microscopic examination and ability to grow through a Craigie tube within $24 \mathrm{hr}$.

' $H$ ' agglutination technique. Agglutinating serum obtained from a rabbit immunized with a saline suspension of motile Escherichia coli strain $\mathrm{K} 12$ was inactivated by heat. Standard methods were used for the preparation of ' $H$ ' and ' $O$ ' agglutinable suspensions and for the Dreyer agglutination test (Mackie \& McCartney, 1948).

\section{RESULTS}

\section{Recombination using motility as selective marker of the $F+$ parent}

Ninety-eight motile streptomycin-resistant recombinants from the mating W677 $\mathrm{F}^{+} \times$Coli $\mathrm{B} / \mathrm{S}^{\mathrm{R}} \mathrm{F}-$ were picked from discrete flares in the semi-solid streptomycin gelatin agar and tested for the unselected markers of the $\mathbf{F}+$ parent, i.e., $\mathrm{T}^{-}, \mathrm{L}^{-}, \mathbf{B}_{\mathbf{1}}^{-}, \mathbf{V}_{1,5}^{\mathrm{R}}, \mathrm{lac},{ }^{-} a \mathrm{rab}^{-}, \mathrm{gal}_{\mathrm{5}}^{-}, x y l^{-}$, and $m t l^{-}$. These recom- 
binants had all the unselected markers of the $\mathrm{F}$ - parent. Control plates of semi-solid gelatin agar containing streptomycin when inoculated with W677 $F+$ alone showed no growth and when inoculated with coli $B / S^{R} F-$ alone never yielded flares, indicating that the $\mathbf{F}+$ parent had not mutated to streptomycin resistance, nor the $\mathbf{F}$ - parent to motility.

' $H$ ' agglutinable suspensions were prepared from these recombinants and from the strain $\mathrm{K} 12$ culture used for the preparation of the agglutinating serum. All suspensions including the $\mathrm{K} 12$ suspension agglutinated to the same titre with the serum prepared against the motile K12 parent; this showed that the flagella of the recombinants and of the $\mathrm{F}+$ parent had the same antigenic composition. Using this technique, neither ' $\mathrm{O}$ ' agglutinable suspensions of $\mathrm{K} 12$ nor saline suspensions of coli $\mathbf{B} / \mathbf{S}^{\mathbf{R}}$ agglutinated with this serum.

On mating $\mathrm{W} 677 \mathrm{~F}+$ and $615 \mathrm{~S}^{\mathrm{R}} \mathrm{F}$ - by the same method it was found that the unselected marker tyr $^{+}$had been transferred from the $\mathrm{F}+$ parent to $10.7 \%$ of the 84 motile, streptomycin-resistant recombinants tested. One of these motile $\mathrm{tyr}^{+}$recombinants was also $\mathrm{arab}^{-}, \mathrm{gal}_{5}^{-}$(see Table 1). No other marker from the $\mathbf{F}+$ parent was found in any of the recombinants. It is concluded that motility is linked to tyr and, less closely, to $a r a b$ and gal $_{5}$.

\section{Table 1. Transfer of unselected markers}

From $\mathrm{F}+$ parent to recombinants on mating $E$. coli $\mathrm{W} 67^{\prime} 7 \mathrm{~F}+\operatorname{motile}\left(\mathrm{T}^{-} \mathbf{L}^{-} \mathbf{B}_{\mathbf{1}}^{-} \mathrm{V}_{1,5}^{\mathrm{R}}, l a c^{-}\right.$,

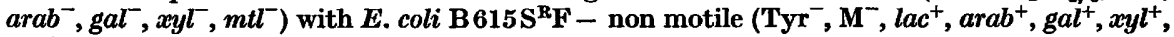
$m t l^{+}$) on streptomycin semi-solid gelatin agar using motility as selective marker of the $\mathbf{F}+$ parent

Unselected $\mathbf{F}+$ markers transferred

\begin{tabular}{ccc}
\hline tyr $^{+}$ & $\mathrm{arab}^{-}$ & $\mathrm{gal}^{-}$ \\
- & - & - \\
+ & - & - \\
+ & + & +
\end{tabular}

Total motile recombinants

\begin{tabular}{cc}
$\begin{array}{c}\text { No. of } \\
\text { recombinants }\end{array}$ & \multicolumn{1}{c}{} \\
74 & $88 \cdot 1$ \\
9 & $10 \cdot 7$ \\
1 & $1 \cdot 2$ \\
84 &
\end{tabular}

+ Indicates transfer of unselected markers from $\mathbf{F}+$ parent. The unselected markers $\mathrm{T}^{-} \mathrm{L}^{-} \mathrm{B}_{1}^{-} \mathrm{V}_{1}^{\mathrm{R}}{ }_{5} \mathrm{lac}^{-}, x y l^{-}, \mathrm{mll}^{-}$were not transferred from the $\mathrm{F}+$ parent to any of the recombinants total.

The rate of recombination was estimated at 1 motile recombinant in $10^{8}$ Escherichia coli strain B cells, but an accurate determination could not be made by the technique of streaking centrifuged deposits on plates.

\section{Recombination using tyr $^{+}$as selective marker of the $\boldsymbol{F}+$ parent}

Samples of a mixture of $\mathrm{W} 677 \mathrm{~F}+$ and $615 \mathrm{~S}^{\mathrm{R}} \mathrm{F}$ - were spread on minimal medium supplemented with methionine, and also on minimal medium supplemented with methionine and streptomycin (to examine the effect of contraselection for streptomycin-sensitivity). It was found that the inclusion of streptomycin reduced the number of recombinants from 1 in $5 \times 10^{5} 615 \mathrm{~S}^{\mathrm{R}} \mathrm{F}-$ cells to 1 in $5 \times 10^{6}$. Control plates seeded with either $W 677 \mathrm{~F}+$ or $615 \mathrm{~S}^{\mathbf{R}} \mathrm{F}-$ alone gave no colonies.

On testing the unselected markers of the recombinants recovered from the methionine minimal plates it was found that only $3.9 \%$ of the recombinant 
clones were streptomycin-sensitive, which suggests that contra-selection was not the sole reason for the reduction in the yield of recombinants when streptomycin was included. Moreover, the presence of streptomycin not only reduced the yield of $\mathrm{tyr}^{+}$recombinants but, with the exception of motility, also significantly effected the relative frequency of the various classes of recombinants (see table 2).

\section{Table 2. Transfer of unselected markers}

From $\mathrm{F}+$ parent to recombinants on mating $E$. coli $\mathbf{W} 677 \mathrm{~S}^{8}$ motile $\mathrm{F}^{+}\left(\mathrm{T}^{-} \mathrm{L}^{-} \mathrm{B}_{1}^{-}, \mathrm{V}_{1,5}^{\mathrm{R}} l a c^{-}, a r a b^{-}\right.$, $\left.g a l_{\mathrm{s}}^{-}, x y l^{-}, m t l^{-}\right)$with $\mathrm{E} . \operatorname{coli} \mathrm{B} 615 \mathrm{~S}^{\mathrm{B}} \mathrm{F}$ - non-motile $\left(\mathrm{Tyr}^{-}, \mathrm{M}^{-}, \operatorname{lac}^{+}, a r a b^{+}, g a l^{+}, x y l^{+}, \mathrm{mtl}^{+}\right)$on minimal medium supplemented with methionine, or methionine and streptomycin, tyr $^{+}$being the selective marker of the $\mathbf{F}+$ parent.

Unselected markers transferred from $\mathbf{F}+$ parent

\begin{tabular}{|c|c|c|c|c|c|c|c|c|}
\hline $\mathbf{V}_{1,5}^{\mathbf{R}}$ & $\operatorname{lac}^{-}$ & motilit & $a a b^{-}$ & $\mathrm{gal}_{5}^{-}$ & $\mathbf{s}^{\mathrm{s}}$ & $x y t^{-}$ & $m t t^{-}$ & $\mathbf{M}^{+}$ \\
\hline- & - & - & - & - & - & - & - & - \\
\hline- & - & - & + & - & - & - & - & - \\
\hline- & - & - & + & + & - & - & - & - \\
\hline- & - & - & - & + & - & - & - & - \\
\hline- & - & + & - & - & - & - & - & - \\
\hline- & - & + & + & - & - & - & - & - \\
\hline- & - & + & + & + & - & - & - & - \\
\hline+ & + & + & + & + & + & + & + & + \\
\hline- & - & - & + & + & + & + & + & + \\
\hline+ & - & + & + & + & - & - & - & - \\
\hline+ & + & - & - & - & - & - & - & - \\
\hline- & - & - & - & - & + & + & - & - \\
\hline - & - & - & - & - & + & + & + & - \\
\hline 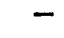 & - & - & + & + & + & + & - & + \\
\hline
\end{tabular}

Total recombinants tested
Supplements to medium

\begin{tabular}{|c|c|c|c|}
\hline \multicolumn{2}{|c|}{ Methionine } & \multicolumn{2}{|c|}{$\begin{array}{l}\text { Methionine and } \\
\text { streptomycin }\end{array}$} \\
\hline No. & $\%$ & No. & $\%$ \\
\hline 80 & $62 \cdot 5$ & 124 & $72 \cdot 5$ \\
\hline 9 & $7 \cdot 0$ & 6 & $\mathbf{3 \cdot 5}$ \\
\hline 10 & $7 \cdot 8$ & 8 & $4 \cdot 6$ \\
\hline 1 & 0.8 & $\mathbf{3}$ & $1 \cdot 8$ \\
\hline 9 & $7 \cdot 0$ & 25 & $14 \cdot 6$ \\
\hline 5 & $\mathbf{3 \cdot 9}$ & $\mathbf{3}$ & $1 \cdot 8$ \\
\hline 7 & $5 \cdot 4$ & 2 & $1 \cdot 2$ \\
\hline 1 & 0.8 & • & - \\
\hline 1 & $0 \cdot 8$ & - & . \\
\hline 1 & 0.8 & . & . \\
\hline 1 & 0.8 & - & - \\
\hline 1 & 0.8 & - & . \\
\hline 1 & 0.8 & - & - \\
\hline 1 & 0.8 & - & - \\
\hline 128 & & 171 & \\
\hline
\end{tabular}

+ indicates transfer of unselected marker from $\mathrm{F}+$ parent.

When $\mathrm{tyr}^{+}$was used as the selective marker from the $\mathbf{F}+$ parent the only frequent ( $>2 \%$ ) class of recombinants obtained were: those with no unselected marker from the $\mathbf{F}+$ parent $(\mathbf{6 2 . 5} \%$ or $\mathbf{7 2 . 5} \%$ ); those with the unselected markers motility (7\% or $14.6 \%)$; arab $(7 \%$ or $3.5 \%)$; arab and gal $5(7.8 \%$ or $4.6 \%)$; motility and $\operatorname{arab}(3.9 \%$ or $1.8 \%)$; motility, arab and gal $(5.4 \%$ or $1.2 \%)$; the percentages for each class being stated for recombinants selected in the absence and in the presence of streptomycin. These frequent classes can be explained as resulting from double, rather than multiple, cross-overs in the region of the tyr locus if the order of the loci concerned is motility-tyr-(arab, gal $_{5}$ ), with none of the other unselected markers tested lying between motility and $\left(a r a b, g a l_{5}\right)$.

\section{DISCUSSION}

Electron micrographs have shown that the cells of Escherichia coli strain B are without flagella and attempts to obtain motile mutants have failed. As a result, it is impossible to find the latent flagellar antigens, if any, of $E$. coli $\mathbf{B}$ for comparison with those of $E$. coli K12. The flagella of the motile progeny 
have the antigenic pattern of $\mathrm{K12}$, the $\mathrm{F}+$ parent. This is in contrast to the salmonellas, where, when motility is transduced to a non-flagellated strain, the latent genes determining the $\mathbf{H}$ antigens of the recipient strain are usually expressed.

From the present data the loci concerned appear to be in the order motilitytyr-( $\left.a r a b, g^{2} l_{5}\right)$. De Haan (1955) using the streptomycin-sensitive parent of this $615 \mathrm{~S}^{\mathbf{R}} \mathrm{F}$ - strain has reported that the linkage results in recombination experiments can be markedly altered by the cultural conditions of the Fstrain and also by the addition of methionine to the medium used for selecting recombinants. It is possible that streptomycin has a similar effect. The action of added streptomycin, in altering the apparent closeness of linkage of arab and of gal $_{5}$ to motility and $t y r$, cannot at present be explained.

I wish to thank Dr P. G. de Haan for the auxotrophic mutants of Escherichia coli strain B, Dr D. Rowley for his interest and encouragement and Miss Margaret Ham for her excellent technical assistance.

\section{REFERENCES}

Clowes, R. C. \& Rowley, D. (1954). Some observations on linkage effects in genetic recombination in Escherichia coli K12. J. gen. Microbiol. 11, 250.

Davis, D. B. \& Mingioli, E. S. (1950). Mutants of Escherichia coli requiring methionine or vitamin $B_{12}$, J. Bact. 60, 17 .

Furness, G. \& Rowlex, D. (1955). Transfer of motility by Escherichia coli $\mathrm{K} 12$ to E. coli B. J.gen. Microbiol. 12, v.

HAAN, P. G. DE (1955). Genetic recombinations in Escherichia coli B. III. The influence of experimental conditions on the transfer of unselected markers. Genetica, 27, 364 .

LEDERBERG, J. (1950). Isolation and characterisation of biochemical mutants of bacteria. Meth. med. Res. 3,5 .

LEnnox, E. S. (1955). Transduction of linked genetic characters of the host by bacteriophage P1. Virology, $1,190$.

Mackie, T. J. \& McCartney, J. E. (1948). Handbook of Practical Bacteriology, 8th ed. Edinburgh: $\mathrm{E}$ and S. Livingstone, Ltd.

Stocker, B. A. D., Zinder, N. D. \& LeDerberg, J. (1953). Transduction of flagellar characters in Salmonella. J. gen. Microbiol. 9, 410.

TulLoch, W. J. (1939). Observations concerning bacillary food infection in Dundee during the period 1923-1938. J. Hyg., Camb. 39, 324.

(Received 24 January 1958) 